\title{
TRABALHO DOCENTE NA EDUCAÇÃO INFANTIL: UMA ANÁLISE DE PESQUISAS ACADÊMICAS NO PERÍODO DE 2000 A 2016
}

\author{
Evanileide Patrícia Lima Figueira ${ }^{1}$, Renata Portela Rinaldi ${ }^{2}$ \\ ${ }^{1}$ Mestranda do Programa de Pós-Graduação em Educação da Universidade Estadual Paulista - UNESP, Campus \\ Presidente Prudente, SP. E-mail: evanileidelima@gmail.com \\ ${ }^{2}$ Doutora em Educação pela Universidade Federal de São Carlos - UFSCar. Professora do Departamento de Educação e \\ do Programa de Pós-Graduação em Educação da Universidade Estadual Paulista - UNESP, Campus Presidente \\ Prudente, SP. E-mail: renata.rinaldi@fct.unesp.br
}

\section{RESUMO}

O Trabalho docente na Educação Infantil, apesar dos avanços alcançados nas últimas décadas, ainda se apresenta como um campo frágil nas pesquisas acadêmicas, com formas de organização e funcionamento que tendem a contribuir para fatores que colaboram para sua precarização, tais como ausência de conhecimentos específicos por parte de muitos profissionais que trabalham com crianças, desvalorização profissional etc. Nesse contexto, temos como objetivo analisar como se apresentam os estudos sobre o trabalho docente na Educação Infantil nas pesquisas acadêmicas no período de 2000 e 2016 . A pesquisa teórica vincula-se a uma pesquisa mais ampla e foi norteada pela abordagem qualitativa, do tipo pesquisa bibliográfica; realizada na base de Dados da Biblioteca Digital de Teses e Dissertações (BDTD). Inicialmente os resultados apontaram 216 trabalhos, que, após análise individual, constatou-se apenas 16 vinculados à Educação Infantil. Os resultados evidenciaram a complexidade do trabalho docente, explicitando a necessidade de ampliar as pesquisas a seu respeito nessa etapa de ensino.

Palavras-chaves: Trabalho docente. Educação infantil. Pesquisa bibliográfica.

\section{TEACHING WORK IN EARLY CHILDHOOD EDUCATION: AN ANALYSIS OF ACADEMIC RESEARCH FROM 2000 TO 2016}

\begin{abstract}
Teaching work in Early Childhood Education is a fragile field in academic research, despite advances in the last decades, being organized and functioning in ways that contribute to its precariousness: many professionals who work with children lack the necessary knowledge, the area is undervalued, etc. In this context, this research aims to understand what academic research produced between 2000 and 2016 reveals on this subject. This theoretical research is linked to a broader research and focused on a qualitative approach to bibliographic research using the Biblioteca Digital de Teses e Dissertações Database (BDTD). At first, 216 works were selected. After individual analysis, only 16 were found to be related to Early Childhood Education. Results show the complexity of teaching work and make clear the need to broaden research on this subject in this stage of learning.
\end{abstract}

Keywords: Teaching work. Early Childhood Education. Bibliographic research.

\section{INTRODUÇÃO}

Os resultados apresentados vinculam-se a uma pesquisa mais ampla em desenvolvimento, que tem como objetivo geral a análise da formação de professores e do trabalho docente nas diferentes etapas da educação básica. 0 embasamento teórico fundamenta-se na compreensão da formação de professores como um processo contínuo que se desenvolve ao longo da vida (MIZUKAMI et al., 2002; RINALDI, 2016) e do trabalho docente, não apenas no âmbito das relações de trabalho, mas de múltiplos aspectos (culturais, organizacionais e formativos) que influenciam a formação e a atuação profissional do professor (MANCEBO, 2007). 
No presente texto temos, portanto, 0 objetivo de analisar como se apresentam os estudos sobre o trabalho docente na Educação Infantil nas pesquisas acadêmicas realizadas no período de 2000 a 2016 e publicadas na base de Dados da Biblioteca Digital de Teses e Dissertações (BDTD).

Para tanto, adotamos o seguinte percurso: em primeiro lugar, traçamos uma breve revisão teórica sobre o tema do trabalho docente e da educação infantil. Posteriormente, apresentamos na seção de metodologia os procedimentos que nortearam a coleta, organização e análise dos resultados obtidos. $\mathrm{Na}$ sequência, apresentamos os resultados obtidos, analisando-os à luz do cotejo com a literatura buscando desvelar 'se' e 'de que forma' o tema tem sido tratado nas pesquisas acadêmicas buscando superar a dicotomia entre o cuidar e o educar nesse nível de ensino. Nas considerações finais, buscamos reiterar as discussões e apresentamos algumas reflexões a partir da retomada do objetivo proposto.

\section{Breve revisão de literatura}

A educação infantil, como primeira etapa da Educação Básica, reconhecida desde a promulgação da Lei de Diretrizes e Bases no. 9.394 de 1996, atualizada em 2017 pelo Senado Federal, ainda tem muitos desafios para serem superados. $O$ direito a esse nível de ensino inclui não apenas o acesso, mas também a qualidade da educação oferecida, e a necessidade de se ter clareza do tipo de educação que se almeja para a construção de uma sociedade mais democrática e justa. Cabe nos indagarmos, até que ponto a educação infantil oferecida responde aos anseios propostos para essa construção de sociedade e às exigências de aprendizagem que respeita $o$ direito das crianças e também dos profissionais que atuam para a promoção do seu desenvolvimento global como seres humanos.

De acordo com Campos, Füllgraf e Wiggers (2006) uma revisão de pesquisas brasileiras divulgadas entre 1996 e 2003 nos principais periódicos de educação e apresentadas nas Reuniões Científicas Anuais da Associação Nacional de Pós-Graduação e Pesquisa em Educação (ANPED) há sérios problemas de qualidade nos diversos tipos de atendimento à demanda da educação infantil no Brasil, nas diferentes regiões do país. Segundo os autores,
Ao mesmo tempo que cresce a demanda por acesso à pré-escola e à creche, os problemas de falta de qualificação do pessoal, de infraestrutura, material precário, de dificuldades na comunidade com as famílias e de falta de orientação pedagógica adequada continuam a ser detectados em creches e pré-escolas públicas, conveniadas particulares. (CAMPOS; FÜLLGRAF; WIGGERS, 2006, p. 93).

Nesta perspectiva, nos propusemos a realizar o estudo com vistas a desvelar 'se' e 'de que forma' o tema do trabalho docente na educação infantil, um dos grandes desafios apontados na pesquisa de Campos, Füllgraf e Wiggers (2006) tem sido tratado nas pesquisas acadêmicas nos últimos 16 anos.

Numa perspectiva histórica constata-se que o status de profissão é adquirido a partir das reinvindicações pelos professores sob a valorização de sua função, justificado pela especificidade e especialidade que a compõe, desencadeando assim a retirada da profissão docente de uma posição secundária, dominada pelos ideais religiosos, configurando-a como ocupação principal, sob o comando do Estado, incorporando a dimensão política em sua ação, tornando-se assim um instrumento possibilitador de ascensão social (NÓVOA, 1999).

Dessa forma, o trabalho docente surge como foco de investigações no Brasil, no final da década de 1970, sob a orientação marxista, com olhar centrado fundamentalmente na natureza do trabalho docente, sua organização e a gestão da escola (MANCEBO, 2007). As alterações sóciopolíticas, econômicas e culturais pelas quais a sociedade passa nas últimas décadas influenciam inúmeras mudanças no enfoque por meio do qual o trabalho do professor passa a ser analisado ao longo dos anos.

Ao final da década de 1990, com as reformas educacionais, o trabalho docente "[...] passa a ser pesquisado articulado às investigações sobre a formação docente e sua "profissionalização"” (MANCEBO, 2007, p. 467). A atividade do professor passa a ser compreendida 
pela complexidade e importância denotada a ela; tendo na figura do professor a possibilidade de realização dos objetivos propostos à educação, a ocorrer na escola, através de seu domínio sobre um conjunto de saberes teórico-científicos; o que gera a necessidade de criação de instituições de formação, assim como a intensificação de estudos voltados para a formação dos professores e sua atuação pedagógica.

Na Educação Infantil, o trabalho atribuído aos profissionais que nela atuam segue uma trajetória demarcada em sua origem pelo caráter assistencialista, pautado no cuidado e proteção da criança, na busca pelo atendimento às necessidades das mães trabalhadoras ou como forma de suprir as carências sociais e culturais na qual as crianças estavam expostas (OLIVEIRA, 2002), sendo a partir da Constituição de 1988 que ocorre o reconhecimento da educação em creches e pré-escolas como um direito da criança a ser mantido pelo Estado, passando a constituirse como primeira etapa da Educação Básica pela Lei Diretrizes e Bases (BRASIL, 1996), assumindo assim seu caráter pedagógico.

Tal assunção em relação à natureza da Educação Infantil e sua intencionalidade educativa coloca em pauta aspectos que perpassam $o$ ato pedagógico e refletem sob a aprendizagem e desenvolvimento da criança em detrimento das suas necessidades peculiares de formação, tais como, organização do espaço, tempo, rotina, currículo e a formação dos profissionais que nela atuam, em nível superior curso de licenciatura plena, admitida, como formação mínima a oferecida em nível médio, na modalidade normal, determinada Lei no 9.494/96 em seu arto. 62.

No entanto, de acordo com Imbernón (2011, p. 46)

[...] a profissão docente desenvolve-se por diversos fatores: o salário, a demanda do mercado de trabalho, o clima de trabalho nas escolas em que é exercida, a promoção na profissão, as estruturas hierárquicas, a carreira docente etc. e, é claro, pela formação permanente que essa pessoa realiza ao longo de sua vida profissional [...] A melhoria da formação ajudará esse desenvolvimento, mas a melhoria de outros fatores (salário, estruturas, níveis de decisão, níveis de participação, carreira, clima de trabalho, legislação trabalhista etc.) tem papel decisivo nesse desenvolvimento.

Nesse sentido, ao buscar uma reflexão sobre o trabalho docente, há de se levar em consideração os diferentes aspectos que o definem e sobre ele interferem, referentes à profissionalidade, cuja formação profissional assume um papel importante na sua definição e autonomia docente, já que esta refere-se "[...] às qualidades da prática profissional dos professores em função do que requer o trabalho educativo" (CONTRERAS, 2002, p. 74).

Ao profissional da educação infantil, tal profissionalidade dialoga com a indissociação entre o cuidar e educar e as especificidades das crianças dessa etapa de ensino, que dado o seu modo peculiar de ser e estar no mundo, reserva a atuação do professor uma singularidade no modo de ensinar e relacionar-se, que delineiam as necessidades da sua atuação, acentuando a importância da formação desse profissional, que para dirigir suas ações e exercer seu efetivo papel deve mobilizar a "[...] racionalização dos conhecimentos e habilidades necessários ao exercício profissional" (RINALDI, 2012, p.33).

As mudanças na natureza da Educação Infantil nos colocam diante de um desafio: o da compreensão de que as instituições, sejam elas públicas ou particulares, tenham como foco as crianças, todas elas com direito a vivenciar boas rotinas, uma jornada diária interessante, acolhedora e desafiadora, bem como atividades que instiguem $o$ desenvolvimento de seu conhecimento sobre relações sociais e elementos da cultura. Isso apresenta também um desafio para a formação dos professores, apontando para a necessidade não apenas da formação específica, 
mas de uma profunda compreensão do que caracteriza educar crianças pequenas e um verdadeiro interesse e competência para desempenhar a função de professores de Educação Infantil (OLIVEIRA, 2012, p.71).

Partindo de tais explicitações, torna-se evidente que o trabalho docente tem suas interfaces ampliadas pela natureza humana do seu objeto de trabalho, e das modalidades de interação entre o trabalhador e objeto (TARDIF, 2009), onde a característica de um (objeto) reflete diretamente sobre a atividade do outro (trabalhador), decorrendo dessa articulação as características e especificidades da profissão, ou seja, sua profissionalidade (IMBERNÓN, 2011).

No entanto, a profissionalidade, como evidencia Imbernón (2011) relaciona-se diretamente às condições que mobiliza a profissão de ensinar, sendo estas referentes à profissionalização, já que situam-se "[...] como a obtenção de um espaço autônomo, próprio à sua profissionalidade" (RINALDI, 2012, p.33).

No que se refere à Educação Infantil, o trabalho docente tem sua configuração construída num processo histórico marcado pelo assistencialismo, em que a intencionalidade educativa é ainda uma dimensão conquistada (BRASIL, 1996) em processo de efetivação. Visto que, o trabalho desenvolvido nesta etapa da educação básica ainda preserva aspectos que remetem à sua origem.

A profissionalização dos educadores que trabalham na educação infantil é um processo cultural que depende da função atribuída à creche e à préescola. Historicamente a formação do docente da área tem sido extremamente pobre ou inexistente,

principalmente a dos que trabalham em creches, área de muita atuação leiga predominantemente

feminina. Isso se deu porque, dentro do quadro de marcantes desigualdades entre as diversas e antagônicas classes sociais existentes em nossa sociedade, a concepção assistencialista, tradicionalmente usada para nortear o trabalho realizado nas creches particularmente naquelas que atendem crianças filhas de família de baixa renda - fez com que pessoas sem qualificação profissional específica fossem recrutadas para cuidar das crianças e interagir com elas. (OLIVEIRA, 2002, p. 23)

Destarte, a definição da profissão docente, esta não deve ser definida a partir de um conjunto de características a priori, pois a busca por tal status pode se materializar como instrumento propulsor da proletarização do trabalho docente, já que não levam em consideração o processo histórico em que as condições de trabalho e as imagens que a representam foram construídas (CONTRERAS, 2002).

Nesse cenário, percebe-se que o trabalho docente acaba por ser desconfigurado de sua finalidade que vai muito além do cuidado. Segundo o Parecer CNE/CEB no 17 de junho de 2012,

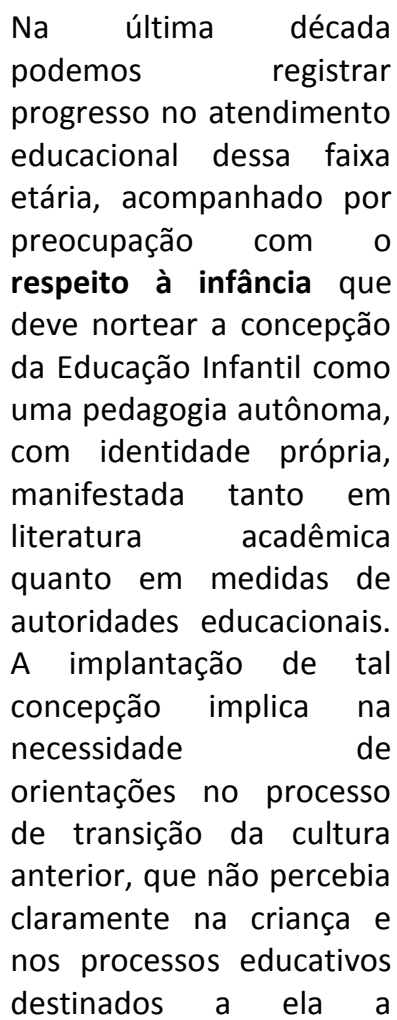


especificidade própria que hoje lhe atribuímos, revelando-se o grande potencial para seu desenvolvimento.

[Entretanto], [...] vem revelando a necessidade de novas orientações em alguns aspectos como a organização e o funcionamento da Educação Infantil (carga horária, turno, jornada, enturmação, material pedagógico, avaliação) e a formação dos profissionais que atuam nessa área. [...] Assegurar uma Educação Infantil de qualidade requer, dentre outros fatores, que a formação inicial dos profissionais que trabalham com crianças, nesta etapa de ensino, Ihes possibilite a apropriação de conhecimentos específicos relativos ao modo de promover desenvolvimento sociocultural das crianças menores de seis anos. (BRASIL, 2012, p. 2).

Portanto, a efetivação de um trabalho de qualidade na educação infantil engloba uma gama de mobilizações que envolvem tanto recursos humanos, referentes à qualificação profissional, quanto os materiais relacionados à estrutura e organização do espaço na qual a criança está inserida, cuja definição de objetivos e metas da proposta educativa deve partir da concepção de criança e infância e da aprendizagem das crianças e não para elas, ou seja, de acordo com suas necessidades de desenvolvimento, o que envolve um processo de rupturas e inovação.

[...] de forma geral, os critérios de qualidade do trabalho na Educação Infantil devem abranger desde as condições de funcionamento das escolas (razão aluno/professor, tamanho de salas, qualidade da alimentação, diversidade de materiais didáticos etc.), às práticas pedagógicas e condições de trabalho e de formação dos diversos profissionais que fazem parte do contexto escolar (OLIVEIRA, 2012, p. 32).

Atualmente, nas instituições de Educação infantil o trabalho docente se estrutura sobre a busca pela indissociação ente o cuidar e educar, devendo se manifestar no processo educativo de forma integrada, eliminando assim a separação de ambos entre o corpo e o cognitivo, tampouco promovendo a hierarquização dos profissionais entre os que ensinam e os que cuidam (BRASIL, 1998.

Kramer (2008) ao discorrer sobre o binômio cuidar e educar coloca em questão o fato deste estar presente somente na educação infantil, e da necessidade em refletir sobre a definição etimológica concernente ao mesmo, que na própria junção acaba por dicotomizar, promovendo assim diferenciação entre as funções desempenhadas pelos profissionais nessa etapa de ensino, onde ocorre "[...] uma divisão de tarefas na qual um profissional habilitado coordena as atividades que ele chama de "pedagógicas", outro profissional (chamado pajem ou monitor [...]) se responsabiliza por ministrar cuidado físico às crianças [...]" (OLIVEIRA, 2012, p. 14).

Outro aspecto que o estrutura é o rompimento com a feminização da profissão, sustentado pelo julgamento de que a atuação nessa etapa restringe-se às mulheres. Tal perspectiva sobre o exercício da função designado preferencialmente às mulheres tem influência do seu processo histórico de constituição, que relaciona desde sua origem as necessidades de cuidado e afeição à figura feminina, num processo simbólico de maternagem, recebendo ao longo do tempo nomenclaturas diversificada como pajem, babá, tia, que simbolicamente reduzem a função dessas profissionais, cujo desempenho esperado delas se assemelhe muito com a das mães, afetando de certa forma o caráter profissional do trabalho desempenhado na educação infantil (SANTOS, 2005, p. 87).

Tal circunstância corrobora com o que expões Oliveira (2002, p. 24) ao afirmar que:

$\begin{array}{lr}\text { Esse } & \text { modelo } \\ \text { familiar/materno } & \text { de }\end{array}$ 


\begin{abstract}
cuidado e educação de crianças pequenas, portanto, nega a exigência de profissionalização. Basta a transposição de competências maternais para orientar o trabalho com o grupo de crianças, embora o modelo envolva uma dimensão nova: a de prestar cuidados remunerados aos filhos alheios. Desse profissional requer-se paciência, capacidade para expressar afeto e firmeza na coordenação do grupo infantil. Pouco se exige em termos de conhecimento mais elaborado acerca das funções da educação infantil e das características

sociohistóricas do desenvolvimento das crianças [...].
\end{abstract}

A Educação Infantil, apesar dos avanços percebidos nas políticas educacionais, ainda apresenta uma realidade que destoa do que propõe a legislação vigente para essa etapa de ensino, configurando seu trabalho de forma assistencialista, e mantendo em seus espaços de atuação profissionais sem a formação adequada, assim como horários de funcionamento e relação professor/aluno que ultrapassam o estabelecido por lei.

No entanto, tal verificação incita uma busca pela compreensão sobre os elementos que se apresentam na respectiva realidade educativa, inviabilizando a sua efetivação; já que o professor não pode se configurar como único agente possibilitador desse processo, na qual, segundo Rinaldi (2012, p. 44):

Tais exigências
verticalizadas apenas na
figura do professor
evidenciam o quadro
atual, de precarização da
profissão, intensificação
do trabalho, baixos
salários, rigorosos
controles burocráticos da
profissão por parte do
Estado, docentes mal
preparados, mal
administrados e, nesse

sentido, é muito difícil esperar que os professores façam um bom trabalho.

Diante do exposto, o objetivo desse trabalho reside em compreender o que revelam as pesquisas acadêmicas de teses e dissertações acerca do trabalho docente na educação infantil, buscando identificar as principais temáticas que são abordadas em suas discussões.

Cabe destacar que, ao assumirmos a pesquisa como fonte de análise e reflexão sobre a forma como a temática em pauta se manifesta nas diferentes realidades não pressupomos a busca por respostas, ou consenso quanto ao que seja exposto, mas a viabilizamos como instrumento mobilizador de questões que incitem reflexões pertinentes às mudanças necessárias corroborando com Campos (2009, p. 281-282) ao destacar que "[...] a pesquisa não pode fornecer respostas prontas ao sistema de ensino. Seus resultados constituem elementos importantes a serem levados em conta nas decisões, mas não são os únicos e nem podem ser incorporados sem mediação".

\section{METODOLOGIA}

Esta produção vincula-se a uma pesquisa mais ampla que tem como foco, o estudo do estado do conhecimento acerca da formação de professores e o trabalho docente nos diferentes níveis de ensino. Especificamente o presente texto analisar como se apresentam os estudos sobre o trabalho docente na Educação Infantil nas pesquisas acadêmicas. A delimitação da temática nesse nível de ensino se justifica, sobretudo no que se refere à organização dos pesquisadores para o levantamento, tratamento e análise dos dados.

Para se alcançar tal finalidade foi adotada a pesquisa bibliográfica como método de investigação (CHIZZOTTI, 2003), utilizando um rigoroso processo de planejamento para a coleta de dados em diversas bases, a saber: Encontro Nacional de Didática e Prática de Ensino (ENDIPE), Associação Nacional de Pós-Graduação e Pesquisa em Educação (ANPED), Associação Nacional de Política e Administração da Educação (ANPAE), Biblioteca Digital Brasileira de Teses e Dissertações (BDTD), Revista Brasileira de Educação e Caderno CEDES. Para o presente texto, apresentaremos os resultados parciais 
derivados de pesquisas acadêmicas na Base de Dados BDTD, no período de 2000 a 2016.

Este processo foi desenvolvido a partir das seguintes etapas: definição de descritores (Trabalho Docente, Trabalho Docente and Educação Infantil) e aplicação dos filtros da Base de Dados: Assunto (de acordo com os descritores), Idioma (Português) e o Ano da publicação (inserindo neste campo o período de 2000 a 2016). Tal refinamento foi aplicado, com o objetivo de delimitar a busca, concentrando os resultados sobre a temática em pauta.

Os resultados para cada descritor foram analisados a partir do acesso ao trabalho completo e considerados somente os que correspondiam à temática investigada. A necessidade e critério em acessar o trabalho na íntegra se deram porque muitos títulos não evidenciavam o assunto abordado na pesquisa, podendo este ficar oculto no título, mas comparecer nas palavras-chave ou resumo.

Posteriormente, foi realizada a leitura na íntegra de todos os trabalhos selecionados e feito o fichamento a partir de um protocolo organizado pela coordenadora da pesquisa. Após, foram estabelecidos alguns indicadores para a análise dos trabalhos selecionados, tais como os temas e subtemas constante nas mesmas, recorrência de abordagem teórico-metodológica etc. Para esse texto, apresentaremos os aspectos contemplados nas discussões dos respectivos trabalhos, ressaltando aqueles relacionados à precarização do trabalho docente a partir das temáticas abordadas.

\section{RESULTADOS E DISCUSSÕES}

Os resultados da pesquisa bibliográfica em investigações acadêmicas nos últimos 16 anos evidenciaram pouca dedicação dos estudiosos sobre a temática do trabalho docente, o que denota a necessidade de intensificação de pesquisas em torno da mesma, já que conforme aponta Tardif (2009, p.38):

A força, mas igualmente a peculiaridade das práticas cotidianas, é que elas reproduzem bem as variáveis do sistema, mas o fazem introduzindo nele constantes

deslocamentos, desorientações, conflitos, desvios, tensões e contradições, cujo peso acumulado dia após dia acaba produzindo, às vezes outra coisa em vez daquilo que as variáveis anunciavam.

O trabalho docente não consiste apenas numa atividade de execução de tarefas, mas de constante atribuição de significados aplicados ás ações e interações com os demais parceiros que o compõem.

Sendo assim, adentrar o cerne do trabalho docente favorece a percepção do real cenário em que $o$ ato de ensinar se efetiva, fugindo à superficialidade do que dispõe a legislação vigente sobre a mesma, onde não é possível perceber a subjetividade e ação do professor, sendo tal aproximação favorável à anunciação de questões e situações que possibilitem mudanças e transformações.

Em uma primeira consulta com os descritores definidos obtivemos um total de 455.867 e deste total, apenas 216 voltados à investigação sobre o tema. Num segundo processamento, evidenciou-se que do total que investigou sobre o trabalho docente, apenas 16 trabalhos voltaram-se à investigação do tema na etapa da Educação infantil.

Os resultados por ano são apresentados no Gráfico 1, em que é possível visualizar um número extremamente reduzido de pesquisas sobre a temática na educação infantil, publicadas nos anos de 2006, 2007, 2010 a 2016 respectivamente. Ou seja, apenas nos últimos 6 anos é que se percebe, apesar do reduzido número, uma regularidade de pesquisas acadêmicas sobre o trabalho docente nesta etapa da educação básica. 
Gráfico 1. Resultados da pesquisa de levantamento bibliográfico na BDTD no período de 2000-2016.

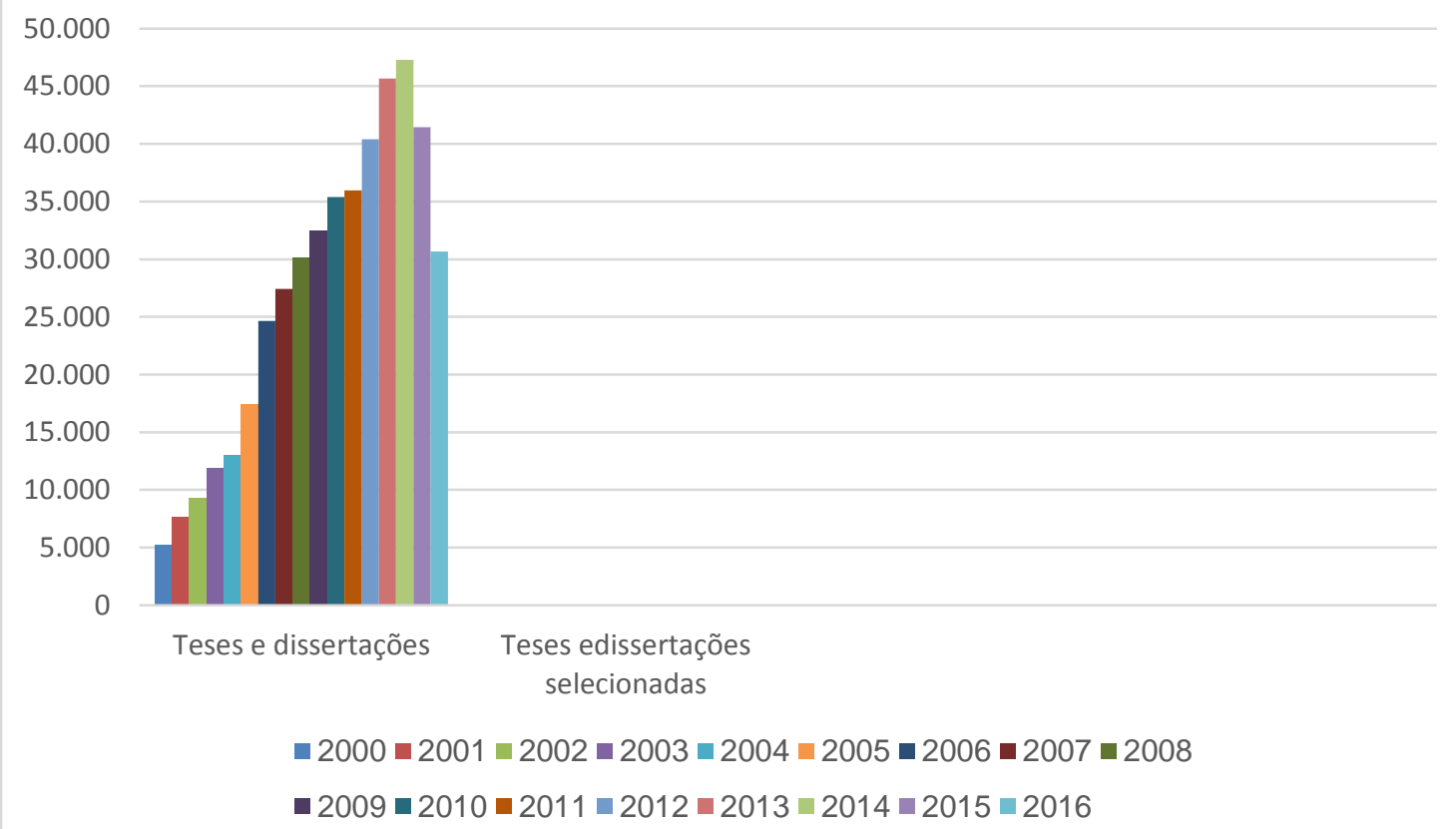

Fonte: Sistematizado pelas autoras a partir processamento dos dados.

O conjunto de produções acadêmicas que investigaram o trabalho docente na educação infantil, 12 dissertações e 4 teses, pode ser observado no Quadro 1.

Quadro 1. Distribuição das teses e dissertações selecionadas para análise.

\begin{tabular}{|c|c|c|c|c|}
\hline Ano & $\begin{array}{l}\text { Tipo de } \\
\text { trabalho }\end{array}$ & Título & Autor & $\begin{array}{c}\text { Filiação } \\
\text { Institucional do } \\
\text { autor }\end{array}$ \\
\hline 2006 & Dissertação & $\begin{array}{l}\text { Pelas telas, pelas janelas: a } \\
\text { coordenação pedagógica e a formação } \\
\text { de professores nas escolas }\end{array}$ & $\begin{array}{l}\text { Renata Cristina } \\
\text { Oliveira Barrichelo } \\
\text { Cunha }\end{array}$ & UNICAMP \\
\hline 2007 & Dissertação & $\begin{array}{l}\text { Cuidado, relações de gênero e } \\
\text { trabalho docente na educação infantil: } \\
\text { um estudo de caso na pré-escola } \\
\text { pública }\end{array}$ & $\begin{array}{c}\text { Eronilda Maria Góis } \\
\text { de Carvalho }\end{array}$ & UFBA \\
\hline \multirow[t]{2}{*}{2010} & Dissertação & $\begin{array}{l}\text { Ludicidade e Resiliência: Como } \\
\text { Professoras de Educação Infantil lidam } \\
\text { com o prazer e o sofrimento no } \\
\text { contexto educativo }\end{array}$ & $\begin{array}{l}\text { Fernanda Almeida } \\
\text { Pereira }\end{array}$ & UFBA \\
\hline & Dissertação & $\begin{array}{l}\text { Valorização da carreira docente: um } \\
\text { estudo sobre a contribuição das } \\
\text { políticas para a profissionalização do } \\
\text { magistério público da educação básica } \\
\text { na Bahia (1997-2006) }\end{array}$ & $\begin{array}{c}\text { Cristiane da } \\
\text { Conceição Gomes de } \\
\text { Almeida }\end{array}$ & UFBA \\
\hline 2011 & Tese & $\begin{array}{l}\text { Os salários dos professores Brasileiros: } \\
\text { Implicações para o Trabalho docente }\end{array}$ & Andreza Barbosa & UNESP \\
\hline 2012 & Dissertação & $\begin{array}{l}\text { Educação infantil: aspectos políticos e } \\
\text { jurídicos nos processos de } \\
\text { intensificação do trabalho do }\end{array}$ & Tiago Soares Alves & UFU \\
\hline
\end{tabular}




\begin{tabular}{|c|c|c|c|c|}
\hline & & $\begin{array}{l}\text { educador infantil no município de } \\
\text { Uberlândia/MG }\end{array}$ & & \\
\hline & Dissertação & $\begin{array}{l}\text { O Mal - Estar Docente: Condições de } \\
\text { trabalho e suas implicações }\end{array}$ & $\begin{array}{l}\text { Roberto Luís de } \\
\text { Oliveira Soares }\end{array}$ & $\begin{array}{c}\text { Faculdade } \\
\text { Est/Rio Grande } \\
\text { do Sul }\end{array}$ \\
\hline 2013 & Tese & $\begin{array}{l}\text { A docência na educação infantil: } \\
\text { representações sociais dos } \\
\text { professores cursistas do proinfantil do } \\
\text { Estado do Rio Grande do Norte sobre } \\
\text { o trabalho docente }\end{array}$ & $\begin{array}{l}\text { Ana Maria Cunha } \\
\text { Aguiar }\end{array}$ & UFRN \\
\hline \multirow[t]{4}{*}{2014} & Tese & $\begin{array}{l}\text { Docência na Educação Infantil: Ofício, } \\
\text { Atividade e Saúde }\end{array}$ & $\begin{array}{l}\text { Francisco Pablo } \\
\text { Huascar Aragão } \\
\text { Pinheiro }\end{array}$ & UFC \\
\hline & Dissertação & $\begin{array}{l}\text { O Hibridismo nas práticas docentes no } \\
\text { Centro de Educação Infantil: entre o } \\
\text { cuidar e o educar }\end{array}$ & $\begin{array}{l}\text { Claudemir Cunha } \\
\text { Lins }\end{array}$ & USP \\
\hline & Dissertação & $\begin{array}{l}\text { Primeiros anos da carreira docente: } \\
\text { diálogos com professoras iniciantes na } \\
\text { educação infantil }\end{array}$ & $\begin{array}{l}\text { Valéria Menassa } \\
\text { Zucolotto }\end{array}$ & UFES \\
\hline & Dissertação & $\begin{array}{l}\text { Auxiliar de atividades educativas na } \\
\text { educação infantil: constituição } \\
\text { histórica e tensões de uma ocupação } \\
\text { no âmbito da rede municipal de } \\
\text { educação de Goiânia }\end{array}$ & $\begin{array}{l}\text { Eliane Garcia de } \\
\text { Brito Edir }\end{array}$ & UFG \\
\hline \multirow[t]{2}{*}{2015} & Dissertação & $\begin{array}{l}\text { Trabalho docente e valorização do } \\
\text { profissional da educação básica: o que } \\
\text { diz a legislação (1996- 2013) }\end{array}$ & $\begin{array}{l}\text { Ana Flávia Gomes } \\
\text { Garcia }\end{array}$ & UFU \\
\hline & Dissertação & $\begin{array}{l}\text { Formação e trabalho das equipes } \\
\text { gestoras de educação infantil }\end{array}$ & $\begin{array}{l}\text { Marcela Lemos Leal } \\
\text { Reis }\end{array}$ & UFES \\
\hline \multirow[t]{2}{*}{2016} & Dissertação & $\begin{array}{l}\text { Relações de gênero e docência na } \\
\text { educação infantil: interfaces entre } \\
\text { políticas públicas e abordagens } \\
\text { pedagógicas }\end{array}$ & $\begin{array}{l}\text { Maria Rita Neves } \\
\text { Ramos }\end{array}$ & UFJF \\
\hline & Tese & $\begin{array}{l}\text { Políticas públicas educacionais e } \\
\text { condições de trabalho na educação } \\
\text { infantil: concepções e vivências de } \\
\text { professoras }\end{array}$ & $\begin{array}{l}\text { Vanessa Cristina } \\
\text { Alvarenga }\end{array}$ & UFU \\
\hline
\end{tabular}

Fonte: Sistematizado pelas autoras a partir processamento dos dados.

Os trabalhos de Almeida (2010) e Garcia (2015) analisam o tema do trabalho docente na Educação Básica e foram selecionados pelo fato de a Educação Infantil se configurar como a sua primeira etapa de ensino, incorporado em 1996 pela Lei de Diretrizes e Bases (LDB) no. 9.9394/96 (BRASIL, 1996), assim como o trabalho de Barbosa (2011) remetida aos professores brasileiros, na qual os professores de educação infantil se incluem.
De modo geral os materiais se caracterizam pela heterogeneidade do enfoque abordado nas discussões das pesquisas, como se observa no Quadro 2. 
Quadro 2. Distribuição das temáticas abordadas nas teses e dissertações.

\begin{tabular}{|l|c|}
\hline \multicolumn{1}{|c|}{ TEMÁTICAS } & QUANTIDADE \\
\hline Identidade profissional & 2 \\
\hline Intensificação e Precarização do trabalho docente & 2 \\
\hline Politicas educacionais sobre trabalho e carreira docente & 4 \\
\hline O Mal - Estar Docente & 2 \\
\hline Trabalho docente na educação infantil & 3 \\
\hline Relações entre gênero e docência na Educação Infantil & 1 \\
\hline Trabalho e processos formativos & 2 \\
\hline
\end{tabular}

Fonte: Sistematizado pelas autoras a partir processamento dos dados.

As pesquisas que abordaram a temática Identidade profissional (CUNHA, 2006; AGUIAR, 2013) e Trabalho docente na educação infantil (EDIR, 2014; LINS, 2014; ZUCOLOTTO, 2014), colocaram em evidência o não reconhecimento pelo profissional de seu efetivo papel, em razão das múltiplas tarefas que tem que assumir, muitas vezes alheias a sua função precípua; os tensionamentos promovidos na prática educativa pela indissociação do cuidar e educar; a disposição de cargos não contemplados em plano de carreira; destacando ainda a complexa tarefa de inserção profissional nessa etapa de ensino.

Outros temas como a Intensificação $e$ precarização do trabalho docente (PEREIRA, 2010; BARBOSA, 2011) e O Mal-Estar Docente (SOARES, 2012; PINHEIRO, 2014) também comparecem nas pesquisas acadêmicas nesta etapa da educação básica. Os resultados obtidos colocaram em pauta discussões sobre as condições em que são desempenhadas o trabalho do professor seja em relação ao salário, infraestrutura, recursos humanos e materiais, que podem contribuir para o mal-estar docente. A esse respeito,

No que se refere às Politicas educacionais sobre trabalho e carreira docente (ALMEIDA, 2010; ALVES, 2012; GARCIA, 2015; ALVARENGA, 2016) foi feito um tensionamento sobre o estabelecimento das políticas educacionais à sua implementação, em seu processo histórico, demostrando a fragilidade das mesmas no seu processo de efetivação; destacando os aspectos que decorrem dessa discrepância, como as formas de contratação temporária, ampliação de oferta sem a valorização efetiva do profissional, afetando diretamente o professor e sua profissão, ou seja, seu profissionalismo. As respectivas constatações localizam-se na observação de Kramer (2006) quando destaca a necessidade em se concretizar a efetivação dos direitos já conquistados.
Ainda sobre esse aspecto, Campos (2009, p. 282) destaca que:

[...] é importante lembrar que muitos dos problemas que vivemos na educação, no país, não se explicam por uma falta de conhecimento sobre o que deve ser feito, mas por uma falta de condições políticas, para viabilizar aquilo que todos sabem que deve ser feito.

A temática Relações entre gênero $e$ docência na Educação Infantil (CARVALHO, 2007) trouxe em suas discussões a relação entre o cuidar e a feminização do trabalho docente nessa etapa de ensino, e a sua intensificação, das condições dadas aos docentes que impossibilitam a realização da indissociação ente cuidar e educar, tais como a presença de salas lotadas, sem nenhuma auxiliar presente que auxilie juntamente com o professor esse processo.

As temáticas, em suas representações quantitativas, foram distribuídas quase de forma uniforme, não se concentrando apenas sobre uma delas. Tal dispersão pode indicar uma aproximação dos pesquisadores à mesma.

Os resultados apresentados denotam a necessidade de maior investigação sobre a temática do trabalho docente, dada a complexidade que o compõe, e as novas demandas e desafios a ele imposto (GATTI; BARRETO; ANDRÉ, 2011), que podem ser facilitadas ou dificultadas perante as condições de trabalho e carreira que interferem diretamente sobre a realização do mesmo e a qualidade do ensino, especialmente na educação infantil, a julgar pela especificidade da mesma.

Sobre esse aspecto André (2010, p. 180) chamou a atenção para o silenciamento de algumas temáticas nas pesquisas, dentre elas "[...] as condições de trabalho, plano de carreira, 
e organização sindical dos docentes" destacando que a lacuna ainda se fazia presente, ao analisar 298 trabalhos em um Levantamento de teses e dissertações no ano de 2007, e verificar que só 10 tinham como foco as condições de trabalho docente.

\section{CONCLUSÃO}

O trabalho docente na Educação Infantil, dada a especificidade que o compõe, reserva aos profissionais que nela atuam uma diferenciação em seu papel, em função da indissociação entre o cuidar e educar, a característica lúdica dessa etapa de ensino e a dimensão afetiva essencial na relação estabelecida com as crianças pequenas.

Tal singularidade, dada às condições em que ocorram, pode colaborar para uma desconfiguração ou desvalorização do papel deste profissional, resguardando a ele prioritariamente a função do cuidar, a ser desempenhado preferivelmente por mulheres ou a ser desempenhado por profissionais sem a mínima qualificação.

A presente intensificação ou sobrecarga do trabalho, decorrente do desempenho de múltiplas funções, ou da compensação de atribuições alheias em decorrência da falta de funcionário; somando se ainda a esses aspectos a desordenada relação adulto/criança, problemas de infraestrutura, plano de carreira, salário e recursos materiais revelados através das temáticas abordadas nas pesquisas aqui analisadas, que denotam ou até denunciam a discrepância presente entre o que propõe as politicas educacionais e as condições dadas na prática para que sejam implementadas colaboram para além da desconfiguração - para precarização do trabalho docente.

Retomando ao objetivo proposto, seja este compreender o que revelam as pesquisas acadêmicas acerca do Trabalho Docente na Educação Infantil nos últimos 16 anos, evidenciamos uma multiplicidade de fatores que perpassam $o$ ato educativo materializado no trabalho docente, cabíveis de serem contemplados, quando se almeja a busca por uma educação de qualidade para as crianças e um trabalho digno para os adultos que ali atuam, que perpassam pela formação docente, mas ultrapassam esse aspecto, demandando a necessidade de olhar para os aspectos sociais, políticos, culturais, éticos, organizacionais entre outros.

\section{REFERÊNCIAS}

AGUIAR, A. M. C. de. A docência na educação

infantil: representações sociais dos professores cursistas do proinfantil do Estado do Rio Grande do Norte sobre o trabalho docente. 2013. $214 \mathrm{f}$. Tese (Doutorado em Educação) - Universidade Federal do Rio Grande do Norte, Natal, 2013.

\section{ALMEIDA, C. C. G. Valorização da carreira}

docente: um estudo sobre a contribuição das políticas para a profissionalização do magistério público da educação básica na Bahia (1997-2006). 2010. 148 f. Dissertação (Mestrado em Educação) - Universidade Federal da Bahia, Salvador, 2010.

ALVARENGA, V. C. Políticas públicas educacionais e condições de trabalho na educação infantil: concepções e vivências de professoras. 2016. 342 f. Tese (Doutorado em Educação) - Universidade Federal de Uberlândia, Uberlândia, 2016.

ALVES, T. S. Educação infantil: aspectos políticos e jurídicos nos processos de intensificação do trabalho do educador infantil no município de Uberlândia /MG. 2012. 184 f. Dissertação (Mestrado em Educação) - Universidade Federal de Uberlândia, Uberlândia, 2012.

ANDRÉ, M. Formação de professores: a constituição de um campo de estudos. Educação, Porto Alegre, v. 33, n. 3, p. 174-181, set./dez.

2010. Disponível em: $<$ http://revistaseletronicas.pucrs.br/ojs/index.ph p/faced/article/view/8075/5719>. Acesso em: 02 fev. 2017.

\section{BARBOSA, A. Os salários dos professores}

Brasileiros: Implicações para o Trabalho docente. 2011. 210 f. Tese (Doutorado em Educação) Universidade Estadual Paulista - Campus Araraquara, Araraquara, 2011.

\section{BRASIL. Constituição (1988). Constituição da}

República Federativa do Brasil. Brasília, DF. 1988. Disponível em:

<http://www.planalto.gov.br/ccivil_03/decretolei/Del5452.htm>. Acesso em 28 jul. 2017.

BRASIL. Lei de Diretrizes e Bases da Educação Nacional. Lei no 9394/96. 1996. Disponível em: $<$ http://portal.mec.gov.br/seesp/arquivos/pdf/lei 9394_Idbn1.pdf >. Acesso em 28 jul. 2017. 
BRASIL. Conselho Nacional de Educação.

Orientações sobre a organização e o funcionamento da Educação Infantil, inclusive sobre a formação docente, em consonância com as Diretrizes Curriculares Nacionais para a Educação Infantil. Parecer 17 de junho de 2012. Brasília: CNE/CEB, 2017.

BRASIL. Ministério da Educação. Referencial Curricular para Educação Infantil. Brasília: 1998. 1.vol.

CAMPOS. M. M. Para que serve a pesquisa em educação?. Caderno de Pesquisa, São Paulo, v. 39, n. 136, p. 269-283, jan./abr. 2009. Disponível em:

$<$ http://www.scielo.br/scielo.php?script=sci_artt ext\&pid=S0100-

$15742009000100013 \& \operatorname{lng}=e n \& n r m=i s o \& t \mid n g=p t>$ .Acesso em 24/01/2018 . DOI

$10.1590 / \mathrm{S} 010015742009000100013$

CAMPOS, M. M.; FÜLLGRAF, J.; WIGGERS, V. A qualidade da educação infantil brasileira: alguns resultados de pesquisa. Cadernos de pesquisa, São Paulo, v. 127, n. 36, p. 87-128, 2006.

Disponível em:

$<$ http://www.scielo.br/scielo.php?script=sci_artt ext\&pid=S0100-

$15742006000100005 \& \operatorname{lng}=e n \& n r m=i s o \& t \operatorname{lng}=e n$. Acesso 24/01/18 . DOI

$10.1590 / \mathrm{S} 010015742006000100005$

CARVALHO, E. M. G. de. Cuidado, relações de gênero e trabalho docente na educação infantil: um estudo de caso na pré-escola pública. 2007. 255 f. Tese (Doutorado em Educação) Universidade Federal da Bahia, Salvador, 2007.

CHIZZOTTI, A. A pesquisa qualitativa em ciências humanas e sociais: evolução e desafios. Revista Portuguesa de Educação, v. 16, n. 2, p. 221-236. 2003.

CONTRERAS, J. A autonomia de professores. Tradução de S. T. Valenzuela. São Paulo: Cortez, 2002.

CUNHA, M. I. O tema da formação de professores: trajetórias e tendências do campo na pesquisa e na ação. Educação e Pesquisa, São Paulo, v.39, n.3, p.609-625, jul./set. 2013.

Disponível em: http://www.scielo.br/pdf/ep/v39n3/aop1096.pdf . Acesso em: 03 fev. 2017.

CUNHA, R. C. O. B. Pelas telas, pelas janelas: a coordenação pedagógica e a formação de professores nas escolas. 2006. $288 \mathrm{f}$. Tese (Doutorado em Educação) - Universidade Estadual de Campinas, Campinas, 2006.

EDIR, E. G. de. B. Auxiliar de atividades educativas na educação infantil: constituição histórica e tensões de uma ocupação no âmbito da rede municipal de educação de Goiânia. 2014. 126 f. Dissertação (Mestrado em Educação) Universidade Federal de Goiás, Goiânia, 2014.

GARCIA, A. F. G. Trabalho docente e valorização do profissional da educação básica: o que diz a legislação (1996- 2013). 2015. 137 f. Dissertação (Mestrado em Educação) - Universidade Federal de Uberlândia, Uberlândia, 2015.

GATTI, B.; BARRETTO, E. S. S.; ANDRÉ, M. Políticas docentes no Brasil: um estado da arte. Brasília: UNESCO, 2011. Disponível em: http://unesdoc.unesco.org/images/0021/002121 /212183por.pdf. Acesso em: 05 fev. 2017.

IMBERNÓN, F. Formação Docente e Profissional - Formar-se para a mudança e a incerteza. 9 ed. São Paulo: Cortez, 2011.

KRAMER, S. Profissionais de educação infantil: gestão e formação. São Paulo: Ática, 2008.

LINS, C. C. O Hibridismo nas práticas docentes no Centro de Educação Infantil: entre o cuidar e o educar. 2014. 127 f. Dissertação (Mestrado em Educação) - Universidade de São Paulo, São Paulo, 2014.

MANCEBO, D. Agenda de pesquisa e opções teórico-metodológicas nas investigações sobre trabalho docente. Educação \& Sociedade, Campinas, v. 28, n. 99, p. 466-482, maio/ago. 2007. Disponível em: <http://www.scielo.br/pdf/es/v28n99/a09v2899. pdf>. Acesso em: 05 nov. 2017.

MIZUKAMI, M. G. N. et al. Escola e aprendizagem da docência: processos de investigação e formação. São Carlos: EdUFSCar, 2002. 
NÓVOA, A. (Org.). Profissão Professor. Portugal: Porto Editora, 1999.

OLIVEIRA, Z. R. Educação Infantil: fundamentos e métodos. São Paulo: Cortez, 2002.

OLIVEIRA, Z. R. (Org.). 0 trabalho do professor na Educação Infantil. São Paulo: Biruta, 2012.

PEREIRA, F. A. Ludicidade e Resiliência: Como Professoras de Educação Infantil lidam com o prazer e o sofrimento no contexto educativo. 2010. 277 f. Dissertação (Mestrado Acadêmico em Educação) - Universidade Federal da Bahia, Salvador, 2010.

PINHEIRO, F. P. H. A. Docência na Educação Infantil: Ofício, Atividade e Saúde. 2014. 275 f. Tese (Doutorado em Educação) - Universidade Federal do Ceará, Fortaleza, 2014.

RAMOS, M. R. N. Relações de gênero e docência na educação infantil: interfaces entre políticas públicas e abordagens pedagógicas. 2016. $186 \mathrm{f}$. Dissertação (Mestrado em Educação) Universidade Federal de Juiz de Fora, Juiz de Fora, 2016.

REIS, M. L. L. Formação e trabalho das equipes gestoras de educação infantil. 2015. $251 \mathrm{f}$. Dissertação (Mestrado em Educação) Universidade Federal do Espirito Santo, Vitória, 2015.

RINALDI, R. P. Formação de professores: algumas considerações sobre o campo de pesquisa. In: MILITÃO, A. N.; SANTANA, M. S. R. (Org.). Intersecções entre pesquisas/pesquisadores experientes e pesquisas/ pesquisadores iniciantes no campo educacional. São Carlos: Pedro \& João Editores, 2016. p. 79-98.

RINALDI, R. P. Formação de professor e profissionalização: aspectos históricos e contextuais. In: TREVISAN, Z; DIAS, C. L. (Org.). Profissionalização: construção do conhecimento e da identidade docente. Curitiba: CRV, 2012. P. 33-48.

SANTOS, M. O. V. dos. A identidade da Profissional de Educação Infantil. In: GUIMARÃES, C. M. (Org.). Perspectivas para educação infantil. Araraquara: Junqueira \& Marin, 2005.
SOARES, R. L. de. O. O Mal-Estar Docente:

Condições de trabalho e suas implicações. 2012. $82 \mathrm{f}$. Dissertação (Mestrado Profissionalizante em Teologia) - Escola Superior de Teologia, São Leopoldo, 2012.

TARDIF, M; LESSARD, C. 0 trabalho docente: Elementos para uma teoria da docência como profissão de interações humanas. 5. ed.

Petrópolis: Vozes, 2009.

ZUCOLOTTO, V. M. Primeiros anos da carreira docente: diálogos com professoras iniciantes na educação infantil. 2014. 159 f. Dissertação (Mestrado em Educação) - Universidade Federal do Espirito Santo, Vitória, 2014

Recebido para publicação em: 01/02/2018

Revisado em: 06/11/2017

Aceito em: 13/11/2017 